Vol. 8 No. 1 Maret 2020, Hal. 265-271

\title{
INOVASI PELAYANAN KESEHATAN PUBLIC SAFETY CENTER 119 (PSC 119) SMASH CARE'S DI KOTA SOLOK
}

\author{
Wike Yuliana $^{1}$, Roni Ekha Putera ${ }^{2}$ dan Yoserizal ${ }^{3}$ \\ Jurusan Administrasi Publik , FISIP, Universitas Andalas \\ 1wike.yuliana@yahoo.com, ${ }^{2}$ roniekhaputera@soc.unand.ac.id, ${ }^{3}$ yoserizal@soc.unand.ac.id
}

\section{INFO ARTIKEL}

Riwayat Artikel:

Diterima: 10-04-2020

Disetujui: 27-04-2020

\section{Kata Kunci:}

1. Inovasi

2. Pelayanan publik

3. Smash Care's
Keyword:

1. Inovation

2. Public service

3. Smash Care's

\begin{abstract}
Abstrak: Inovasi pelayanan kesehatan yang dikenal dengan Public Safety Center 119 (PSC 119) SMASH CARE's di Kota Solok diluncurkan dalam rangka meningkatkan kualitas pelayanan publik di bidang kesehatan bagi masyarakat yang kurang mampu. Adapun tujuan dari penelitian ini adalah untuk mengetahui pelaksanaan SMASH CARE's yang diterima oleh masyarakat Kota Solok. Pendekatan dalam penelitian ini adalah deskriptif kualitatif. Sumber data primer dan sekinder. Teknik pengumpulan data yang dipergunakan adalah wawancara dan dokumentasi. Sedangkan hasil penelitian ini menunjukkan bahwa PSC 119 Smash Care's memberikan layanan kegawatdaruratan kepada masyarakat Kota Solok atau yang sedang berada di Kota Solok. Layanan ini sangat membantu masyarakat. Selain itu layanan ini mempunyai kelebihan jika dibandingkan dengan layanan sebelumnya yang hanya menerima pasien di faskes, sedangkan layanan ini memberikan kemudahan akses layanan dengan menelepon secara langsung ke nomor 119 serta proses pemberian layanan 24 jam dan tidak dipungut biaya serta sesuai dengan kebutuhan dan mempertimbangkan keluhan masyarakat. Namun masih terdapat beberapa kekurangan seperti adanya nomor iseng menghubungi call center 119, kurangnya sarana dan prasarana serta masih kurang maksimalnya sosialisasi.
\end{abstract}

ABSTRAK

\section{Abstract:}

Health service inovation Public safety Center 119 (PSC 119) Solok Madinah Sehat Cara Revolusi Sehat (SMASH CARE'S) in Solok City. For increasing the service in health sector, the govermnent of Solok City launched an inovation in health service PSC 119 Smash Care's. this research intended to find out the implementation of Smash Care's and also the public services that accepted by solok society. This research is using descriptive approach by qualitative methods. Technique of collecting the data was by interview and documentation. The result of this research shows that PSC 119 Smash Care's give the emergency services to Solok society or the people who are in the Solok City. This service is very assist for the society. In the other hand, this service has more advantage than other. Those are easy to acces the service by direct call to 119 and also giving 24 hours service, free of charger and in accordance with needs and taking into account community complaints. But there are still some shortcomings such as the fraudulent numbers to call center 119, the lack of facilities and infrastructure as well and the lack of maximum socialization. 


\section{LATAR BELAKANG}

Saat ini pelayanan yang paling banyak dibutuhkan oleh masyarakat adalah pelayanan di bidang kesehatan selain pangan dan juga pendidikan. Hal ini tidak lepas dari adanya kebutuhan masyarakat untuk tetap bisa memiliki penghidupan yang sehat. Sehingga dengan demikian dibutuhkan pelayanan kesehatan yang memadai guna mendukung pola tersebut. Namun kenyataan yang dihadapi oleh masyarakat dewasa ini adalah layanan yang didapatkan tidak merata selain itu juga masih perlunya perbaikan sarana dan prasarana serta peningkatan akses layanan kesehatan kepada masyarakat, terutama yang ekonomi lemah dan kurang mampu.

Sekarang ini, terjadinya persaingan semakin ketat di semua aspek kehidupan, dimana semua pihak dituntut untuk memberikan yang terbaik agar menjadi nomor satu dan menjadi pilihan masyarakat, termasuk di dalamnya adalah organisasi. Ogranisasi pemerintah yang terkenal lamban, berbelit-belit dalam pelayanan dituntut bergerak lebih cepat dan tepat agar dalam pemberian layanan dapat memberikan pelayanan yang 'excellent". Untuk itu organisasi pemerintah dalam hal ini kembali dihadapkan pada kenyataan bahwa harus mengetahui segala kebutuhan masyarakat sehingga perlu melakukan perubahan-perubahan dalam menjawab tantangan tersebut. Perubahan yang dimaksud tersebut dikenal juga dengan sebuah inovasi.

Suatu perubahan dalam bentuk inovasi menjadi keharusan dalam pelayanan publik. Inovasi pelayanan publik merupakan terobosan pelayanan publik yang merupakan gagasan ide kreatif original dan adaptasi/modifikasi memberikan manfaat bagi masyarakat baik secara langsung maupun tidak langsung. Dengan kata lain, inovasi pelayanan publik sendiri tidak mengharuskan suatu penemuan baru yang bersifat kontekstual dalm arti inovasi tidak terbatas dari tidak ada kemudian muncul gagasan dan praktik inovasi, tetapi dapat berupa inovasi hasil dari perluasan maupun peningkatan kualitas pada inovasi yang ada (Peraturan Menteri Pendayagunaan Aparatur Negara dan Reformasi
Birokrasi, 2014) . Berdasarkan hasil penelitian Inovasi Pelayanan Publik di Kecamatan Sungai Kunjang Kota Samarinda oleh Dayang Erawati Djamrut mengatakan Kecamatan Sungai Kunjang Kota Samarinda dalam memberikan pelayanan kepada masyarakatnya dengan cepat, tepat, dan tidak dipungut biaya serta tidak mempersulit urusan yang mudah. (Djamrut, 2015).

Salah satu terobosan yang dibuat oleh Menteri Kesehatan Republik Indonesia adalah meluncurkan Program PSC 119. Adapun program ini adalah layanan cepat tanggap darurat kesehatan. Program dari Layanan ini dibentuk tahun 2016 bekerja sama dengan Kementerian Perhubungan untuk membantu penanganan kesehatan terhadap masyarakat yang berhubungan dengan kecelakaan dan situasi kritis (Depkes.go.id. Layanan 119, 2016). Adapun dalam peluncuran layanan PSC 119 ini merupakan kolaborasi nasional antara Pemerintah Pusat dengan Pemerintah daerah, dimana terjadi integrasi layanan antara Pusat Komando Nasional atau National Command Center (NCC) yang berada di kantor Kementerian Kesehatan, Jakarta, dengan PSC 119 yang berada di tiap kabupaten/kota salah satunya Kota Solok dalam program PSC 119 Smash Care's.

Adapun program Smash Care's ini adalah bentuk pelayanan kesehatan yang dilakukan dengan mengunjungi rumah 24 jam, secara berkesinambungan dan komprehensif yang diberikan untuk individu dan keluarga dalam rangka untuk menangangi kasus kegawatdaruratan di masyarakat.

Untuk itu tujuan dari Program PSC 119 Smash Care's (Peraturan Walikota Solok, 2017):

1) Adanya jaminan pemenuhan hak dasar masyarakat dalam pelayanan kesehatan masyarakat dalam rangka mempertahankan, meningkatkan atau memaksimalkan akibat dari penyakit untuk mencapai kemampuan individu secara optimal

2) Adanya jaminan terhadap perlindungan kepada masyarakat dan petugas kesehatan dalam memberikan pelayanan 
3) Meningkatkan peran dan dukungan keluarga, masyarakat, dan Pemerintah Kota terhadap keberhasilan pembangunan kesehatan.

Untuk kriteria pelayanan Smash Care's adalah pelayanan umum yang dapat dikategorikan semua jenis layanan kesehatan secara umum, semua penyakit yang dialami oleh pasien dan tidak mengunjungi fasilitas pelayanan kesehatan, termasuk pasien pasca stroke, penyakit degenerative (hipertensi), luka diabetic, luka pasca bedah, dan penyakit tidak menular lainnya. Sedangkan untuk kriteria pelayanan khusus adalah semua pasien dengan kondisi emergency (gawat darurat).

Sistem kerja pelayanan ini adalah dengan cara pemanggilam melalui saluran telepon dengan nomor 119, yang nantinya akan terhubung langsung ke call center yang siaga 24 jam di Kantor Dinas Kesehatan Kota Solok. Petugas akan meminta keterangan awal terkait keluhan dan lokasi pasien/korban untuk kemudian dilakukan upaya dan penanganan yang cepat dan tepat kepada pasien. Dalam rangka mendukung dan memaksimalkan jalannya program ini, tentu diperlukan peningkatanpeningkatan dan pembenahan dari segala aspek. Pemko Solok pun secara bertahap telah berupaya dalam peningkatan dan pemenuhan aspek dan unsur penunjang diantaranya, dua unit mobil ambulan yang stand by/ disiagakan di Pusat Pelayanan Ibu dan Anak Tanah Garam dan Puskesmas Nan Balimo.

\section{Tinjauan Pustaka Pelayanan Publik}

Pelayanan Publik atau pelayanan umum didefinisikan sebagai segala bentuk jasa layanan, baik dalam bentuk barang publik maupun jasa publik yang pada prinsipnya menjadi tanggungjawab dilaksanakan oleh instansi pemerintah di pusat, di daerah dan di lingkungan Badan usaha milik Negara atau badan usaha milik daerah dalam rangka upaya pemenuhan kebutuhan masyarakat maupun dalam rangka pelaksanaan ketentuan perundang-undangan (Ratminto, 2006). Selain itu pelayanan publik juga diartikan sebagai suatu pelayanan atau pemberian terhadap masyarakat yang berupa penggunaan fasilitas umum, baik jasa mupun non jasa, yang dilakukan oleh organisasi publik dalam hal ini adalah pemerintah dengan segenap kelengkapan kelembagaannya (Arif, 2008). Sadu Wasistiono (2003) berpendapat bahawa pelayanan publik adalah pemberian jasa baik oleh pemerintah maupun pihak swasta atas nama pemerintah ataupun pihak swasta kepada masyarakat dengan atau tanpa pembayaran guna memenuhi kebutuhan atau kepentingan masyarakat. Sementara itu Menurut Kotler dalam Samparan Lukman, pelayanan adalah setiap kegiatan yang menguntungkan dalam suatu kumpulan atau kesatuan, dan menawarkan kepuasan meskipun hasilnya tidak terkait pada suatu produk secara fisik (Lukman, 2000). Sedangkan Lewis dan Gilman (2005) mengatakan bahwa pelayanan publik itu adalah kepercayaan terhadap publik, dengan memberikan pelayanan secara bertanggung jawab sesuai dengan ketentuan perundang-unfangan yang berlaku. Selanjutnya istilah layanan publik berasal dari Bahasa Inggris Public yang berarti umum, masyarakat, Negara. Pelayanan publik sering disebut sebagai pelayanan konstitusional. Pernyataan ini disebabkan oleh butir-butir yang ada dalam konstitusi dari negara yang menyebutkan bahwa negara berkewajiban memberikan berbagai fasilitas yang layak kepada warga negaranya. Dari konstitusi 165 negara yang ada di dunia ditemukan bahwa 116 mengatur hak warga negara untuk memperoleh Pendidikan, 73 diantaranya mengatur hak untuk memperoleh pelayanan kesehatan, 95 konstitusi mengatur hak warga negara untuk memperoleh Pendidikan gratis dan 29 konstitusi yang mengatur hak warga negara untuk memperoleh pelayanan kesehatan gratis (Nurmandi, 2010). Jadi pelayanan publik adalah suatu kegiatan memberikan pelayanan kepada masyarakat yang mempunyai kepentingan pada suatu tempat sesuai dengan aturan dan tata cara yang telah ditetapkan.

\section{Inovasi Pelayanan Publik}

Istilah inovasi berasal dari bahasa latin Innovare yang berarti merubah sesuatu menjadi baru. Sementara itu, istilah inovasi (innovation dan innovate) sendiri baru mulai dikenal dalam kosakata Bahasa Inggris pada abad ke-16. dalam hal ini inovasi dipahami sebagai proses penciptaan produk (barang atau jasa) baru, pengenalan metode atau ide baru atau penciptaan perubahan atau perbaikan yang 
incremental (Suwarno, 2008). Drucker mengartikan inovasi sebagai "change theat creates a new dimension of performance". pada pengertian tersebut dipahami inovasi perubahan yang membuat sebuah dimensi baru dari kinerja (Wibawa, 2009). Dalam hal lain bahwa inovasi itu adalah adalah kegiatan yang meliputi seluruh rangkaian proses dalam menciptakan dan menawarkan jasa atau barang baik yang sifatnya baru, tidak lebih baik atau lebih murah dibandingkan dengan yang tersedia sebelumnya, sehingga dapat memberikan kepuasan kepada masyarakat/pelanggan.

Berdasarkan pengertian inovasi yang telah disebutkan dapat dipahami bahwa inovasi adalah suatu kegiatan yang menciptakan sebuag ide baru yang tujuannya mengubah sesuatu baik berupa produk atau jasa menjadi lebih baik dari sebelumnya. Berikut ini dapat dilihat beberapa hal yang terkait dengan pengertian tentang inovasi pelayanan yang dikemukakan oleh para ahli antara lain: Muluk (2008) membagi inovasi pelayanan menjadi dua kategori yaitu Sustaining Innovation (inovasi terusan) dan Discontinues Innovation (inovasi terputus), sedangkan Mulgan dan Albury (Dalam Muluk, 2008) membagi inovasi pelayanan menjadi tiga level inovasi yaitu: Inovasi Inkremental, Inovasi Radikal dan Inovasi Transformatif, sementara itu (Muluk, 2008) juga mengkategorikan inovasi pelayanan publik menjadi lima tipologi inovasi sektor publik, yaitu Inovasi Produk Layanan, Inovasi Proses Layanan, Inovasi Metode Layanan, Inovasi Kebijakan dan Inovasi Sistem

Adapun dalam penelitian ini peneliti menggunakan istilah inovasi Menurut Suwarno (2008:16-18) yang mengatakan bahwa inovasi mempunyai satu sifat mendasar yaitu sifat kebaruan. Sifat kebaruan ini merupakan ciri-ciri dasar inovasi dalam menggantikan pengetahuan, cara, objek, teknologi atau penemuan yang lama, yang sudah tidak efektif dalam menyelesaikan suatu masalah atau menjawab suatu kebutuhan tertentu. Walaupun tidak ada satu kepahaman defenisi mengenai inovasi, namun secara umum dapat disimpulkan bahwa inovasi mempunyai atribut sebagai berikut:

a) Relative Advantage atau keuntungan Relatif; Sebuah inovasi harus mempunyai keunggulan dan nilai lebih dibandingkan dengan inovasi sebelumnya. Selalu ada sebuah nilai kebaruan yang melekat dalam inovasi yang menjadi ciri yang membedakannya dengan yang lain.

b) Compability atau Kesesuaian; Inovasi juga mempunyai sifat kompatibel atau kesesuaian dengan inovasi yang digantinya. Hal ini dimaksud agar inovasi yang lama tidak serta merta dibuang begitu saja, selain karena alasan faktor biaya yang tidak sedikit, namun juga inovasi yang lama mejadi bagian dari proses transisi ke inovasi yang baru. Selain itu juga dapat memudahkan proses adaptasi dan proses pembelajaran terhadap inovasi itu secara lebih cepat.

c) Complexity atau Kerumitan; Dengan sifatnya yang baru, maka inovasi mempunyai tingkat kerumitan yang boleh jadi lebih tinggi dibandingkan dengan inovasi sebelumnya. Namun demikian, karena sebuah inovasi menawarkan cara yang lebih baru dan lebih baik, maka tingkat kerumitan ini pada uumnya tidak menjadi masalah penting.

d) Triability atau Kemungkinan Dicoba; Inovasi hanya bisa diterima apabila telah teruji dan terbukti mempunyai keuntungan atau nilai lebih dibandingkan dengan inovasi yang lama. Sehingga sebuah produk inovasi harus melewati fase "uji publik", dimana setiap orang atau pihak mempunyai kesempatan untuk menguji kualitas dari sebuah inovasi.

e) Observability atau Kemudahan Diamati; Sebuah inovasi harus juga dapat diamati, dari segi bagaimana ia bekerja dan menghasilkan sesuatu yang lebih baik.

\section{METODE PENELITIAN}

Pendekatan penelitian yang dipergunakan dalam penelitian ini adalah deskriptif kualitatif. Sumber data berasal dari data primer dan sekunder. Teknik pengumpulan data yang digunakan adalah wawancara dan dokumentasi. Wawancara dilakukan dengan pihak-pihak terkait dengan pelaksanaan program yaitu Dinas Kesehatan Kota Solok, Dokter, Puskesmas, Perawat. Teknis analisis data dalam penelitian ini dilakukan dengan cara kualitatif yaitu berlangsung bersamaan dengan bagian-bagian lain 
dari pengembangan penelitian kualitatif, yaitu penegumpulan data dan penulisan temuan (Neuman, 2014). Tujuan dari analisis data adalah meringkaskan data dalam bentuk yang mudah dipahami dan mudah ditafsirkan sehingga hubungan antara masalah penelitian dapat diuji dan dipelajari.

\section{Hasil dan Pembahasan}

Smash Care's yang merupakan layanan kesehatan yang melakukan kunjungan rumah 24 jam berkesinambungan dan komprehensif yang diberikan kepada individu dan keluarga ditempat tinggal mereka yang bertujuan untuk menangani kasus kegawatdaruratan di masyarakat. Kriteria pelayanan Smash Care's ada dua, yaitu Kriteria Pelayanan Umum adalah semua penyakit yang dialami pasien dan tidak dapat mengunjungi fasilitas pelayanan kesehatan, termasuk pasien pasca stroke, penyakit degenerative (Hipertensi), luka diabetic, luka pasca bedah, dan penyakit tidak menular lainnya. Kriteria Pelayanan Khusus adalah semua pasien dengan kondisi emergency (gawat darurat).

Kriteria masyarakat yang dilayani PSC 119 Smash Care's adalah masyarakat Kota Solok, berdomisili di Kota Solok, dan mempunyai Kartu Tanda Penduduk (KTP) dan Kartu Keluarga (KK) Kota Solok. Masyarakat yang membutuhkan pertolongan kegawatdaruratan menghubungi Call Center 119 yang berada di Dinas Kesehatan. Petugas akan menanyai masyarakat penyakit dan lokasi tempat tinggal pasien. Selanjutnya, call center akan menelepon petugas Smash Care's yang terbagi 2 posko. Pemilihan posko berdasarkan alamat tempat tinggal pasien. Petugas Smash Care's akan langsung datang kerumah pasien dan menangani kasus pengobatan dirumah, jika tidak memungkinkan dan membutuhkan pertolongan lebih lanjut maka pasien akan dirujuk ke Puskesmas atau Rumah Sakit tergantung permintaan pasien.

\section{Relative Advantage atau Keuntungan Relatif}

Keuntungan relatif adalah salah satu indikator dalam atribut inovasi pelayanan publik yang digunakan untuk mengrtahui suatu nilai kebaruan yang ada di dalam inovasi pelayanan publik tersebut. Keuntungan dari program ini untuk menjawab pelayanan kegawatdaruratan yang dirasa belum maksimal. Sebelumnya pelayanan kegawatdaruratan belum dapat ditangani dengan baik, seperti daerah yang sulit dijangkau atau berada jauh dari pusat kota minim untuk mendapatkan pelayanan kesehatan. Dengan adanya program ini sangat membantu masyarakat.

Prosedur pelayanan kesehatan sebelum adanya Smash Care's, tenaga kesehatan hanya menunggu ditempat, tetapi berbeda setelah adanya program Smash Care's. Dengan menerapkan metode jemput bola, sekarang masyarakat yang menunggu dirumah/ditempat. Lalu tenaga kesehatan dari Smash Care's akan datang kerumah. Disisi lain, dari ekonomi keunggulan program ini memiliki sarana dan prasarana yaitu ambulans. Sebelumnya masyarakat yang akan menggunakan ambulnas akan dikenakan biaya, tetapi sekarang masyarakat tidak perlu mengeluarkan biaya karena pelayanan yang diberikan gratis.

Alur pelayanan PSC 119 Smash Care's tertuang dalam Perwako Nomor 63 Tahun 2017 tentang pembentukan PSC 119 Smash Care's Pasal 9 bahwa prosedur pelayanan PSC 119 Smash Care's sebagai berikut:

- Pasien/ keluarga pasien meminta pelayanan PSC 119 Smash Care's melalui call center 119 dan dihubungkan ke call center di puskesmas di daerah tempat tinggal pasien

- setelah menerima telepon dari pasien/ keluarga, tim pelaksana PSC 119 Smash Care's yang ada di puskesmas mengunjungi pasien untuk melakukan pelayanan sesuai dengan kondisi pasien

Dalam sebuah inovasi harus memiliki nilai lebih yang melekat dalam inovasi itu sendiri. Berdasarkan alur pelayanan PSC 119 Smash Care's dapat dilihat bahwa inovasi ini memiliki nilai lebih yaitu dalam kemudahan pelayanan yang diberikan.

Tidak hanya mekanisme pelayanan yang mudah, inovasi PSC 119 Smash care's juga memberikan pelayanan yang dilaksanakan 24 jam dengan pembagian kerja menjadi 3 shift, dapat dilihat berdasarkan tabel berikut:

Tabel 1 Pembagian Shift Layanan PSC 119

\begin{tabular}{|c|c|}
\hline \multicolumn{1}{|c|}{ Shift } & Waktu \\
\hline Dinas Pagi & $07.30-14.00$ \\
\hline
\end{tabular}




\begin{tabular}{|l|r|}
\hline Dinas Sore & $14.00-21.00$ \\
\hline Dinas Malam & $21.00-07.30$ \\
\hline
\end{tabular}

Sumber: Data Olahan Peneliti, 2019

Berdasarkan tabel 1 dapat dilihat bahwa adanya pembagian shift layanan PSC 119 Smash Care's 24 jam. Hal ini menunjukkan salah satu keunggulan dari inovasi ini adalah masyarakat yang mengalami kasus kegawatdaruratan dapat mengakses pelayanan PSC 119 Smash Care's selama 24 jam ditunjukkan adanya tiga shift layanan baik itu pada waktu pagi hari, siang hari maupun malam hari dengan menghubungi call center 119 dan bebas biaya.

\section{Compability atau Kesesuaian}

Kesesuaian adalah indikator yang kedua dalam atribut inovasi. Indikator kesesuaian ini menjelaskan kecocokan inovasi yang baru dibuat oleh instansi terkait apakah masih sesuai dengan standar pelayanan yang sudah melekat dalam instansi tersebut. Sistem jemput bola yang terapkan oleh Dinas Kesehatan dalam menjalankan PSC 119 Smash Care ini sesuai dengan kebutuhan masyarakat. Karena selama ini akses pelayanan kesehatan di Kota Solok tidak merata dan masih banyak masyarakat yang sulit mengakses sarana pelayanan kesehatan.

\section{Tabel 2}

\section{Perbandingan Pelayanan Kesehatan Sebelum dan Sesudah Dilakukannya Inovasi}

\begin{tabular}{|l|l|}
\hline \multicolumn{1}{|c|}{ Sebelum Inovasi } & \multicolumn{1}{c|}{ Sesudah Inovasi } \\
\hline Masyarakat & Tim pelaksana PSC 119 \\
kesulitan untuk & Smash Care's langsung \\
datang langsung ke & mendatangi masyarakat ke \\
fasilitas kesehatan & rumah dan tidak perlu \\
karena kendaraan & datang langsung ke fasilitas \\
tidak ada atau jarak & kesehatan \\
yang jauh ke & \\
puskesmas atau & \\
rumah sakit & \\
\hline $\begin{array}{l}\text { Masyarakat } \\
\text { mengeluarkan biaya }\end{array}$ & Tidak perlu mengeluarkan \\
jika ingin & \\
menggunakan & \\
sarana ambulan & \\
\hline
\end{tabular}

Sumber: Data Olahan Peneliti, 2019
Berdasarkan tabel 2, dapat dilihat bahwa inovasi PSC 119 Smash Care's dilakukan dengan sistem jemput bola ke lapangan. Tentunya ini sangat sesuai dengan kebutuhan masyarakat di Kota Solok. Jika pelayanan sebelumnya dilakukan secara reguler maka inovasi PSC 119 Smash Care's ini hadir sebagai penyempurna inovasi sebelumnya dengan penggunaan teknologi seperti telepon dan internet.

\section{Complexity atau Kerumitan}

Kerumitan adalah tingkatan sasaran inovasi dalam memahami suatu hal baru, memerlukan waktu dan proses untuk memahaminya. Dalam menjalankan inovasi pelayanan PSc 119 Smash Care's didukung dengan tersedianya sarana dan prasarana untuk memudahkan pelayanan yang diberikan kepada masyarakat seperti tersedianya ruangan khusus call center di Dinas Kesehatan Kota Solok yang dilengkapi dengan meja, kursi, laptop operasional dan printer. Selain itu, sarana penunjang terlaksananya pelayanan PSC 119 Smash Care's ini adalah tiga $\mathrm{Hp}$ android yang diberikan untuk masing-masing posko. Namun masih terdapat kendala yang dialami dalam melakukan pelayanan Smash Care's ini seperti adanya nomor iseng yang menelepon ke call center. Selain permasalahan tersebut, hambatan lain yang juga terdapat dalam inovasi ini adalah belum adanya motor layanan PSC 119 Smash Care's yang digunakan untuk pelayanan ke rumah masyarakat yang susah di jangkau dengan kendaraan roda empat.

\section{Triability atau Kemungkinan Dicoba}

Indikator keempat dalam atribut inovasi ini menjelaskan bahwa suatu inovasi harus dapat diuji dan dicoba apakah sasaran inovasi ini telah merasakan keunggulan dari hadirnya inovasi tersebut, dan berguna untuk perbaikan di masa yang akan datang. Diketahui bahwa PSC 119 Smash Care's ini sudah diresmikan pada tanggal 30 November 2017. Pada saat itu, Dinas Kesehatan Kota Solok melakukan sosialisasi tentang adanya inovasi PSC 119 Smash Care's. sosialisasi dilakukan di Dinas Kesehatan. Dan petugas Smash Care's juga melakukan sosialisasi pada care free day. Petugas mengenalkan inovasi ini kepada masyarakat. 
Untuk melihat kepuasan masyarakat terkait program ini maka pihak Dinas Kesehatan membagikan kuisioner atau bertanya langsung kepada masyarakat untuk melihat feedback dari masyarakat terhadap program ini. Jadi hasil yang didapat, masyarakat merasa puas dengan pelayanan Smash Care's ini dibandingkan pelayanan kesehatan sebelumnya

\section{Observability atau Kemudahan Diamati}

Observability adalah proses pengamatan yang dilakukan untuk menggambarkan bagaimana inovasi yang baru diciptakan bisa menghasilkan dampak yang lebih baik dan berjalan sesuai dengan harapan instansi selaku pencipta inovasi. Berdasarkan peelitian yang dilakukan, pelayanan ini mudah diamati oleh masyarakat sehingga masyarakat mudah menggunakan pelayanan kesehatan Smash Care's. Untuk menggunakan pelayanan pun sangat mudah bagi masyarakat, karena masyarakat hanya perlu menelepon call center 119 lalu petugas Smash Care's akan datang. Hal ini terbukti dengan meingkatnya jumlah kunjungan yang dilayani tim PSC 119 Smash Care's dari awal diluncurkannya inovasi hingga saat ini. Berikut tabel jumlah kunjungan tim PSC 119 Smash Care's Kota Solok.

\section{Tabel 3 Jumlah Kunjungan Tim PSC 119 Smash} Care's di Kota Solok

\begin{tabular}{|c|c|}
\hline Tahun & Jumlah (orang) \\
\hline 2018 & 574 \\
\hline 2019 & 852 \\
\hline
\end{tabular}

Sumber: Data Olahan Peneliti, 2019

Berdasarkan tabel 3 dapat dilihat bahwa meningkatnya jumlah kunjungan tim PSC 119 Smash Care's dalam melayani pasien membutuhkan pelayanan kesehatan yaitu dari tahun 2018 sebanyak 574 orang kemudian meningkat pada tahun 2019 menjadi 852 orang. Dengan meningkatnya jumlah kunjungan membuktikan bahwa inovasi PSC 119
Smash Care's semakin dikenal oleh masrakat dan tentunya masyarakat dapat menikmati kemudahan pelayanan yang diberikan dengan adanya inovasi ini. Pada awal peluncuran program ini sudah dilakukan sosialisasi kepada masyarakat, namun sosialisasi yang dilakukan dirasa belum maksimal karena belum semua masyarakat mengetahui inovasi PSC 119 Smash Care's.

\section{Kesimpulan}

Dapat diambil kesimpulan bahwa inovasi PSC 119 Smash Care's ini sudah bisa diterima masyarakat dan dapat berjalan dengan baik. Dilihat dari masyarakat yang menggunakan program ini. Dengan adanya inovasi ini masyarakat sangat terbantu, baik dalam segi waktu dan ekonomi. Layanan kegawatdarurat ini membantu masyarakat Kota Solok dan masyarakat yang sedang berada di Kota Solok. Karena mekanisme pelayanan yang mudah, cukup dengan menelepon call center 119 tersedia 24 jam tanpa biaya apapun. Dari kelima indikator dijelaskan banyak keuntungan yang didapatkan masyarakat dengan hadirnya PSC 119 Smash Care's, tetapi dalam hal sosialisasi pihak Dinas Kesehatan kurang proaktif dalam memperkenalkan inovasi yang dilakukan kepada masyarakat.

\section{Daftar Pustaka}

Ananda, Bobi Rizki, R E Putera dan Ria Ariany (2019). Reformasi Birokrasi Pelayanan Publik di Polres Solok Kota, Transparansi: Jurnal Ilmiah Ilmu Administrasi Vol 2, No. 2, Desember 2019, pp. 217-223.

Ananda, Bobi Rizki, R E Putera dan Ria Ariany (2019). Inovasi Pelayanan Kesehatan Di Rumah Sakit Umum Daerah Kota Pariaman, Publik (Jurnal Ilmu Administrasi) Vol 8 (2), Desember 2019 pp. 167-179.

Arif, Syaiful (2008). Paradigma Pelayanan Publik, Dalam Reformasi Pelayanan Publik, Malang: Averroes Press

Depkes.go.id. Layanan 119. (2016). Terobosan Keagawatdaruratan Medik di Indonesia.

Djamrut, D. E. (2015). Pelayanan Publik di Kecamatan Sungai Kunjang Kota Samarinda. Mahasiswa Universitas Mulawarma, 3. 
Lewis, Carol W. dan Stuart C. Gilman (2005). The Ethics Challenge in Public Service: A Problem-Solving Guide. Market street, San Fransisco: Jossey-Bass

Lukman, S. (2000). Manajemen Pelayanan. Jakarta: STIA LAN Press.

Muluk, K. (2008). Knowledge Management, Kunci Sukses Inovasi Pemerintahan Daerah. Malang: Bayumedia.

Neuman, W. L. (2014). Qualitative and Quantitative Approaches Seven Edition, Pearson Education Limited. United States of America.

Nurmandi, Achmad (2010). Manajemen Pelayanan Publik, Yogyakarta: PT. Sinergi Visi Utama

Ratminto dan Atik Septi Winarsih (2005). Manajemen Pelayanan, Yogyakarta: Pustaka Pelajar

Peraturan Menteri Pendayagunaan Aparatur Negara dan Reformasi Birokrasi. Pedoman Inovasi Pelayanan Publik., Pub. L. No. 30 (2014).

Peraturan Walikota Solok. Pembentukan Public Safety Center 119 Solok Madinah Sehat Cara Revolusi Sehat (SMASH CARE'S)., Pub. L. No. 63 (2017).

Suwarno, Yogi. (2008). Inovasi di Sektor Publik. Jakarta: STIA LAN.

Wasistiono, Sadu (2003). Kapita Selekta Manajemen Pemerintahan Daerah, Bandung: CV. Fokusmedia.

Wibawa, S. (2009). Administrasi Negara: Isu-isu Kontemporer, Graha Ilmu. Yogyakarta: Graha Ilmu. 